\title{
Soft interventionism: A Hayekian alternative to libertarian paternalism
}

Nick Cowen ${ }^{1}$ and Aris Trantidis ${ }^{2}$

\begin{abstract}
Are behavioral interventions consonant with a free society? Rizzo and Whitman argue that behavioral interventions aimed at addressing self-harms are premised on an unrealistic neoclassical account of rationality. We show that the rejection of neoclassical assumptions is warranted but does not exhaust the case for what we call "soft interventionism." Following Hayek's emergent account of human action and defense of a defined role for legislation to address social challenges in commercial spontaneous orders, we argue that soft interventionism is a less intrusive form of state intervention to tackle the blurred boundaries between externalities and internalities. Nudges can be justified so long as the interventions are proportionate, based on subsidiarity and scientifically informed.
\end{abstract}

Keywords: nudges, libertarian paternalism, Hayek, market process, Austrian economics, autonomy, classical liberalism

JEL Codes: D62, D80, D91, B53

Acknowledgements: We would like to thank Malte Dold and the reviewers for their useful comments as well as the Institute for Humane Studies for supporting this project.

\footnotetext{
${ }^{1}$ University of Lincoln, School of Social and Political Sciences, Brayford Campus, Lincoln LN6 7TS, United Kingdom. Email: ncowen@lincoln.ac.uk

${ }^{2}$ University of Lincoln, School of Social and Political Sciences, Brayford Campus, Lincoln LN6 7TS, United Kingdom. Email: atrantidis@lincoln.ac.uk
} 


\section{Introduction}

There is a tension within classical liberalism. Classical liberals revere individual autonomy but also affirm a great society where individuals rely on the knowledge and decisions of countless others that they will never meet (Hayek 1960). For the most part, these two commitments are aligned. The successful use, and resulting dissemination, of specific knowledge in the marketplace, leads to the realization of profit for those whose specific knowledge and contributions turn out to be valuable for meeting the needs of others (Hayek 1945; 2014). Nevertheless, this paradigm of social cooperation through free choice appears to break down occasionally in the form of poor outcomes for individuals produced by chronically bad decision-making. Examples of these are particularly salient when it comes to behavior with bad long-term outcomes for personal health and finance. This mismatch or miscalculation whereby an individual choice fails to take into account all the expected long-term outcomes associated with it is a negative internality (Allcott and Sunstein 2015). A classic example is the mismatch between a smoker's express intention to quit for the sake of their long-term health and their momentary decisions to continue smoking thus reinforcing their habit (Cherukupalli 2010).

The most prominent solution, and increasingly influential in public policy, is offered by "libertarian paternalism," which attempts to preserve ultimate freedom of choice while nevertheless encouraging better decisions (Thaler and Sunstein 2009; Halpern 2016). The premise of libertarian paternalism is that it is possible to manipulate predictably some consequential choices through non-coercive "nudges" to increase the individual's welfare. A nudge is an indirect way of encouraging or reinforcing a putatively beneficial behavior that does not, at least at the moment it is applied, attempt to influence the agent consciously. In this sense, it contrasts with explicit rules backed by sanctions as well as attempts at education or provision of information that attempt to influence the agent's conscious decision processes. For proponents, the fact that minor variations in logically irrelevant elements of a choice situation can influence decisions unconsciously is strong evidence of a failure of individuals to engage in rational choice (Kahneman and Tversky 1979; 1984; Kahneman 2011). If people's supposed preferences revealed through their choices are logically incoherent and cannot produce an efficient path to achieving a reasonable plan, they could be trivially improved 
through greater alignment with a plan set by policymakers that is, arguably, in people's real interests (Sunstein 2021).

Rizzo and Whitman (2019) challenge this paradigm on several dimensions. Their core argument is that the new paternalists judge individual decision-making against an unrealistic baseline of formal rationality drawn from neoclassical economic theory. While this account of rationality has some useful predictive properties in specific contexts, it has never represented a good description of actual human choice, nor does it offer an appropriate normative aim for humans to pursue. From this perspective, Rizzo and Whitman highlight the fragility and imprecision of empirical findings used to justify libertarian paternalism. They point out how reliant the case for policy interventions is on the ability of policymakers to fine-tune their response to biases that vary from individual to individual. Moreover, they argue that libertarian paternalists can seldom identify the "real" settled preferences of the people whose welfare they aim to improve; that is the preferences that would theoretically take full account of long-term personal benefits and costs of each decision as the individual herself assesses them. So, like their old paternalist forbears, libertarian paternalists are pushing their own preferences on the population even if it is through the use of more subtle strategies. Moreover, closer inspection in people's approaches to choices reveals that intuitive reliance on apparently irrelevant contextual cues can be perfectly rational and efficient (Rizzo 2019). For example, an individual may adopt diet rules that only apply in some (logically irrelevant) contexts, yet it may still be effective at improving their health (Rizzo and Whitman 2019, 249). Moreover, due to the more remote, sometimes perverse, feedback that people receive as policymakers, the biases within bureaucratic and democratic processes could be worse than the alleged benefits of paternalist policies (Rizzo and Whitman 2019, 330; cf. John 2018). Rizzo and Whitman (2019, 325) describe the excessive regulation of relatively safe e-cigarettes, driven partly by tobacco companies and suppliers of other smoking cessation products as one result of such biases.

Significantly, Rizzo and Whitman argue that introducing paternalist policies has its own institutional momentum; they are subject to slippery slopes. As a result, behavioral interventions that appear benign or useful can alter the social and policy environment such that more forceful interventions then become easier to justify. This includes interventions that would have been rejected by the original proponents of a nudge. Their solution is consistent adherence to classical liberal limits on state action. They are optimistic that voluntary means are capable of discovering and disseminating the relevant information that people need to make personal lifestyle decisions, combined with the information embedded in emergent customs in 
a free society (Rizzo and Whitman 2019, 237). Indeed, free choices must be permitted so that individuals are capable of discovering their own preferences (cf. Delmotte and Dold 2021).

We defend some behavioral interventions aimed at addressing self-harms, particularly in contexts where internalities and externalities are empirically entwined. We make our case without recourse to neoclassical premises but with more realistic foundations inspired by Hayek's theory of mind. It is a mark of civilization that each individual can meet many complex needs without dedicating much personal thought to them (Hayek 1960). What Hayek calls the marvel of the market is that it allows people to coordinate based on summary information supplied through the competitive pricing of goods and services, combined with consumer experience and the spontaneous sharing of information that stem from societal interactions without a central coordinating source. However, sometimes the decision practices that people adopt spontaneously based on these uncoordinated processes may be seen as insufficient, particularly in a rapidly changing technological and institutional environment.

This challenges Rizzo and Whitman's skepticism of such interventions. Our argument is structured as follows. First, we offer a Hayekian account of rationality and contrast it with the neoclassical account, showing that Hayek's ecological account can acknowledge cases where our ordinary decision-making is likely to depart from choices that represent our selfinterest properly understood and could be improved from some guidance from public institutions. Second, we introduce our proposed framework for assessing policy. We label our approach "soft interventionism." We use "soft" to denote our valuing of non-coercive behavioral changes, which classically include nudges and default options as part of choice architecture but could also include sin taxes that fall short of outright or de facto prohibitions backed by penalties. We use "interventionism" in place of "paternalism" because our approach avoids authorizing unilateral influence and manipulation in favor of a transparent and reasoned approach that emphasizes the procedural constraints of proportionality, subsidiarity, and contestability in scientific debate, as well as the substantive aim of enhancing individual liberty, as the basis for regulatory interventions. This relieves the tension between the classical liberal commitment to individual liberty and admiration of the complex social order that relies on an ever-increasing division of knowledge which means people's autonomy is inevitably mediated by the decisions of countless others. Third, we illustrate the power and ubiquity of soft interventions in road traffic management where the concepts of internality and externality are inseparably integrated into public concerns over health and safety. Finally, we use the example of soft interventions to reduce accidental overdose and suicide as a paradigm example of proportional interventions that are compatible with liberal commitments. 


\section{Rationality: True and False}

Hayek $(1945 ; 1937)$ is famous for his epistemic justification for market institutions premised on considering cooperation among strangers as an example of a spontaneous order (Boettke 2018; 2002). This is where individuals seeking their own ends within a framework of rules end up producing complex forms of coordination across time and space that no single agent could possibly conceive by themselves. By contrast, no planned economy, or government-controlled society, could ever achieve the same degree of coordination as a free society based on the rule of law whatever the intentions of those officially in control of government institutions (Hayek 2007). This is because a central planner would lack access to the knowledge about all social resources and their potential uses that individuals acting within a market process know collectively albeit in a dispersed form.

A distinctive feature of Hayek's $(1937$; 1945) account is the idea that a spontaneous order of mutually beneficial interactions emerges through interactions and processes of trial and error. It contrasts with neoclassical premises that people act independently with consistent preferences and perfect information (Weintraub 1993). This downplays the existence of formative social interactions that shape the preferences and behavior of individual actors over time. Hayek's account of emergent knowledge and social coordination among individuals has important parallels with his account of individual cognition (Cowen 2020; Caldwell 2004). Hayek problematizes not only the notion of society as a unitary agent capable of pursuing a general will but also the notion that individual human beings themselves possess a core "agent" that can observe the external world at given moments, process relevant knowledge, and thus decide an appropriate course of action (Dold and Lewis 2021). What is more, anticipating advances in neuroscience (Fuster 2011), Hayek (1952) argues that our everyday perception and cognition is the result of pattern recognition, honed through receiving positive and negative feedback from successful and failed predictions of observable reality. Hayek (1981) employs a useful distinction between concrete orders, the irreducibly complex objects and events that stimulate our raw sensory experience, and abstract orders, the categories of thought (or models) that we develop to make sense of what we perceive. The vast majority of this cognitive work is unconscious. The separating of a holistic sensory experience into discrete events in time and objects of perception is not naturally given but rather the result of learning how to categorize patterns of sensory spatial and temporal arrangements. We are only ever consciously aware of a small portion of this activity in our minds, yet it is the basis for our reasoning involving our individually distinct and limited capacity for rational thought. As is the case for the extended 
order of society, our degree of rational consciousness is an emergent outcome of piecemeal adaptation to the phenomena we encounter. The reason for this is that even apparently primitive sense-data, objects and their characteristics that we apprehend through our senses, are only rendered meaningful to us through abstract categories, themselves the product of learning to navigate our physical and social world, as well as acculturation through shared language. We rely more on a continuous experience of trial and error rather than formal cognition and analysis.

This learning process extends to social interactions that create systems of customary law and norms of social behavior (Hayek 1982a, 3:158). Hayek understands that evolutionary developed laws form part of the shared understandings that act upon people's behavioral choices. Social and economic actors are therefore constrained or at least guided by emergent properties of a higher level which their own interactions and the prior actions of others generate. From this perspective, Hayek challenges the behaviorist view that we can scientifically predict people's reactions in response to simple external stimuli and his approach stresses the social context from which information useful for our choices emerge, and the heuristic guidance that people rely on when making everyday decisions. Heuristics are essentially rules of thumb that allow people to make good enough decisions based on the information they find salient (Gigerenzer 2008).

If this position is accepted (and there is at least a plausible contemporary scientific basis for this description), it has important consequences for how we evaluate internalities and whether regulation can plausibly improve individual choice. For example, Kahneman (2011) distinguishes between two thinking styles: System 1 and System 2. System 1 is fast, automatic and reliant on heuristics to make decisions. System 2 is slower, relying on gathering relevant information and calculating expected outcomes over a longer time period. Although both systems can suffer from biases, System 1 is supposed to be particularly susceptible to predictable errors, such as present bias or different decision outcomes in the presence of irrelevant alternatives or information. Demonstrated by laboratory experiments, this is supposed to be the mechanism through which internalities in the real-world are produced. Following the Hayekian account, we believe System 2 thinking cannot be so separated from System 1. The world is too complex for any human being to have a truly synoptic grasp of every aspect of the environment, no matter how careful and alert they are. Rather, we are paying attention to a different set of patterns and apply different heuristics and rules of decisionmaking. Our thinking still involves reliance on simplified models of reality to predict future 
outcomes. This way of thinking offers no warrant that it will produce optimal outcomes. The patterns we rely on might still allow us to be deceived or be subject to manipulation, including by the very biases that supposedly mainly effect System 1 .

Moreover, from this perspective, it is a mistake to judge System 1 based on laboratory experiments (Rizzo and Whitman 2019, 34). A system premised on rapid pattern recognition for acting within a familiar environment will produce sub-optimal decisions when placed in a novel environment, especially one which is being deliberately controlled and manipulated (Buturovic and Tasic 2015; cf. Rizzo and Whitman 2019, 188). But real-word decision-making generally offers many opportunities to learn. Hence, when opportunities to learn through feedback have been available, these biases are often reduced or eliminated through the evolutionary development of both norms and commonly held heuristics and guidance. Moreover, from a more dynamic perspective, thinking that can appear biased in a static snapshot of an experiment, can constitute a fallible choice but will trigger a learning process and could lead to new useful heuristics and best practices (Rizzo and Whitman 2019, 29).

What does this mixed and dynamic perspective on thinking and reasoning suggest for establishing cases where some degree of regulation might be appropriate? Rather than assuming a persistent set of biases in human thinking that can be predictably corrected, this perspective suggests we should generally enable actors to figure out through experimentation, feedback, and imitation, what choices best suit their interests. This process is effectuated through their social interactions, including market transactions driven by exchange of goods and services, and of relevant information about them. In some contexts, the sharing of knowledge is more likely to happen at a collective rather than individual level and policymakers should turn their attention to specific choice environments that remain resistant to the spontaneous learning of individuals despite their own ongoing interactions (cf. Rizzo and Dold 2020).

There is some overlap between these problematic choice environments and the problem areas that paternalists are apt to highlight and assert their case for government intervention. For example, many new paternalists are concerned about the long-term consequences of unhealthy diets and lack of exercise for illness and obesity. Looking at this case from a Hayekian perspective, we can acknowledge that post-industrial society has placed many of us in a novel choice environment where calorific food is widely and virtually instantly available while requirements to exert energy are much reduced. Sometimes our biological constitutions, honed through evolution to build up bodily fat reserves in times of plenty, may not produce the kind 
of spontaneous negative feedback that would encourage us to control our weight in an environment where food scarcity is unlikely to be a source of poor health (Bellisari 2008). Nevertheless, acknowledging obesity as a legitimate concern does not immediately prompt regulatory intervention. Once the problem of poor diet is recognized, both market and private associational solutions emerge to refine the choice environment, making it easier for people to be informed about healthy diets and adopt healthier lifestyles should they wish. Even when it appears that the state has a potentially positive role to play in improving individual decisions, the ineliminable nature of state coercions means that it must be adopted with care. We set out how to introduce soft interventions carefully in a way consonant with Hayek's broader theory of human learning and the generation of information. In the next section, we show how such interventions can fit with the principles of liberal constitutional government.

\section{Constraints on intervention}

Congruent with his spontaneous order thesis, Hayek (1973) argued that many useful social rules emerged through individual interactions but acknowledged legislation as sometimes necessary to address flawed laws developed by customs that produced iniquitous outcomes (cf. Schliesser 2021; Scheall 2020). Hayek only insisted that legislators align their lawmaking with the "natural" form of emergent law. Hayek distinguishes between law understood as the emergent outcomes of historical attempts at cooperation, and legislation that involves the deliberate intervention of lawmakers. Legislation is mostly confined to making laws governing the administration of public services, leaving the rest of civil society to manage disputes using general rules discovered and interpreted by judges. Hayek establishes some principles for what those interventions should look like. They should always aim to facilitate autonomous social cooperation and a competitive market rather than to displace it (Hayek 1982b, 2:24). In The Road to Serfdom, Hayek $(2007,90)$ referred to this aim as planning in order to facilitate competition. Formally, legal reforms should take the form of general rules, applicable to all, and not the imposition of arbitrary authority to manage disputes. While the liberal state can alter the content of rules (nomos) of a regime (Hayek 1973, 1:71), they cannot alter their generality, so they become commands (thesis) (Hayek 1973, 1:127).

In other work, we argue that competitive democratic processes and a pluralist civil society play a distinctive role in protecting individual liberty, which was not consistently recognized by Hayek himself (Trantidis and Cowen 2020). Competitive democracy is required to prevent citizens from being subject to explicit political coercion (Acemoglu and Robinson 2019), which may take the form of the manipulation of an individual's situation through 
targeted sanctions and rewards to ensure they support a political party (Trantidis 2015). This applies to nudge interventions since their implementation can be used to punish or privilege private actors (for example, by directing consumers towards the consumer products of politically favored firms).

How should a particular concern with maintaining a framework where autonomous private activities are protected be interpreted in light of proposed behavioral interventions? We suggest three principles that sum up what we consider core commitments of liberal constitutionalism (Buchanan and Congleton 2003, 187-95; Cowen 2021, 130; Pennington 2008; Buchanan 2001; Popper 1945; Aligică, Boettke, and Tarko 2019). Interventions should respect subsidiarity (Pennington 2008; Aligică, Boettke, and Tarko 2019; Buchanan and Congleton 2003; Buchanan 2001), proportionality (Barnett 2004), and be made and revised on a scientific basis (Popper 1945; Schliesser 2019). Policies aimed at addressing internalities must meet these principles to be justified in a classical liberal framework.

\section{Subsidiarity}

Within liberal constitutionalism, subsidiarity is the general principle that the governance solution to social problems should be established and implemented at the lowest feasible scale complementary to learning and voluntary activity by other associations and jurisdictions. This is important both for prioritizing self-governance and facilitating personal and collective learning about personal harm. Harms against the person correspond to a core of rights which most classical liberals recognize as "natural" (although they may not believe them to have a naturalistic origin) but also extend to areas where the personal and public interact, such as infectious disease, increased risk of bankruptcy, levels of pollution, traffic congestion, climate change and other issues of human security.

Our notion of a classical liberal principle of subsidiarity for nudges first highlights the priority of private and voluntary solutions to informational problems. A subsidiarity test examines whether government actions are needed as complementary to what society already knows and disseminates as publicly available information about harmful behavior. To which extent is that information available, accessible and sufficient to inform adult consumers and users of good and services about risks and potential harm from our own behavioral choices?

In the case of internalities, the costs are born by the individual, so we would presume a high degree of scope for individual learning and local solutions amidst adults with full capacity to consent. The reason why subsidiarity is a key check on state actions from a classical liberal 
perspective is that that the information and decisions costs associated with the internality are linked to free choice and personal responsibility. Often, information that is important for their choices is efficiently provided by private providers of goods and services. In case it is not, collective action, such as public warnings or default options, may be needed to upgrade the level of information and allow them to make a more informed, yet still free, choice. Nudges also attempt to manipulate the choice environment to influence momentary decision-making such as to smoke or to buy cigarettes in cases where actors might not be mindful of this information.

Moreover, the subsidiarity constraint must help prevent nudges from becoming a mechanism for a majority stigmatizing the stereotypical activities of a minority. For instance, nudges to discourage smoking will pass the test of subsidiarity if smokers, as individuals and as a community of interest, approve of attempts to highlight the harms relating to their habit, and the tobacco industry does not do so. This applies particularly when many smokers are trying to quit smoking and many of them would have discouraged their loved ones from starting to smoke. A nudge applied at the moment of decision to purchase cigarettes is not manipulative if they were introduced as part of a democratic discussion where smokers themselves were included and generally approved of it. Although not everyone individually impacted may agree with the intervention, they are, at least, forewarned that a nudge is apt to be applied.

By contrast, an intervention premised on discouraging smokers but supported only by non-smokers would, in our view, fail that test. For example, in the United Kingdom, a great many problematized lifestyle differences have a class dimension, with middle-class policymakers focusing attention on consumption and conduct in working-class households and communities (Lawler 2005). Nutt (2009) pokes fun at some proponents of drug prohibition by conceptualizing horse-riding as "equasy," a fictional drug associated with much higher risks to personal safety than the real drug ecstasy. Horse-riding, a statistically dangerous hobby, attracts little concern from hard or soft paternalists because it is a leisure activity of the middle and upper classes who are presumed to be capable of rationally assessing the trade-off between pleasure and risk. Yet, novel leisure activities or those associated with the working classes or urban youth are presumed to be problematic (cf. S. Cohen 2011). Subsidiarity requires that the relevant community affected by the intervention approves of its aims. The ideal of subsidiarity, which it can necessarily only approach in practice, is that the distinction between external manipulator and the agent subject to manipulation is broken down such that interventions constitute a form of collective self-governance rather than paternalism (Buchanan 2000, 118). 


\section{Proportionality}

Proportionality is the principle that interventions should not exceed what is necessary to achieve a publicly approved goal. While subsidiarity scrutinizes the extent to which relevant individuals or a community approve of a policy goal, proportionality checks whether an intervention is the least invasive way to achieve an informational improvement when deemed necessary under subsidiarity. The test of proportionality assesses the intensity of the imposed state restrictions in the sphere of individual freedom, as restrictions or manipulations cannot be overwhelming and arbitrary but only necessary to accomplish an informational deficiency identified under the subsidiarity principle. In the classical liberal framework, defining a case for public intervention is limited by the subsidiarity principle while proportionality adds a dimension of scrutiny for the measures proposed to do so.

Proportionality in a classical liberal framework requires that authorities use only regulation that is appropriate for the publicly approved intended result with the least degree of intrusion on the freedom to act. Hence, not only should the state establish a declared public interest, but it should justify the degree of intervention. The notion that bad personal habits should be "eliminated" through manipulation and continuous ratcheting of interventions would generally not pass such a test of proportionality. Often, the proportionate level of intervention would involve actions by public authority to complement public knowledge rather than more invasive measures such as additional taxes on goods and services or strict regulations on their geographical provision. For instance, restricting the time when shops can sell alcohol or restricting sale to designated shops must be examined in terms of their proportionality to achieve their publicly approved aim against the inevitable limitations on liberty and leisure. To which extent do these restrictions affect moderate users of alcohol or users with lower income as opposed to helping others tackle their alcohol problem or preventing new cases of alcohol abuse?

Proportionality is justified by a Hayekian perspective that expresses concern with legislation that is designed to address internalities while imposing an excessive restriction on freedom of transaction. Insofar as they shift the benefits and burdens of knowledge between actors and associations within civil society, they should be aimed at facilitating improvement and learning through voluntary action. They should generally not be used just to improve social welfare from the policymaker's perspective, but primarily to make it easier for individuals to discover and pursue their own understanding of their welfare. 


\section{Scientific basis}

Finally, we add the prerequisite that the test of subsidiarity and proportionality must be backed by scientific evidence about behaviors that, either individually or collectively, cause harm, and with evidence offering compelling and contestable indications that the type of intervention enacted is effective in informing agents about those facts without imposing significant costs on already informed consumers and users.

Why require a scientific basis? Despite its flaws, science has become by far the most reliable source of explanation and understanding compared to all other available alternatives such as religious authority, magic, superstition and intuition, due to the strictest methodological treatment and scrutiny by an epistemic community (Tullock 1987; Polanyi 2000). Hence, scientific conclusions, though subject to revision, will check the extent of the problem claimed by policymakers and the means they have chosen to address it. By referring to science, the rationale for policymaking is not depoliticized as such but, at least, refers to a methodologically distinct sphere of inquiry when assessing claims of harm.

Why should science have this moderating effect? In liberal democratic systems, no single political organization can control scientific research that occurs around the world by multiple centers, despite inevitable efforts to support specific teams and advantage particular research programs in their constituencies. In the end, as Rizzo and Whitman recognize, misconceptions and manipulations are exposed. The scientific community is international and pluralist enough to challenge poor-quality research. It applies stricter methodological criteria and, unlike public agencies, can expose scandalous use of poor evidence by vested interests. Science coupled with a pluralist political environment offers a check on the biases and rational excesses of political power. Our position is not that policymakers should be led by "the science" but rather that the normative aims of a policy must be tempered and constrained by scientific evidence.

This way, science can challenge unjustified bureaucratic decisions in cases that Rizzo and Whitman $(2019,317-18)$ cite on alleged consumer irrationality concerning energyefficient choices used to justify regulation. Indeed, it was scientific evidence that cast doubt on the definition of obesity thresholds by the WHO, the presumption that e-cigarettes function as a gateway to smoking and the original prescriptions of the food pyramid (Rizzo and Whitman 2019, 321-29). Evidence can thus tame the interventionist bias which Rizzo and Whitman warn about. This was the case when the US Court of Appeals for the DC Circuit overturned the FDA's proposal for graphic warnings on cigarette packs because there was limited evidence for their effectiveness. At the same time, the inevitable consequence of a policy proposal is the 
stirring of reactions from vested interests, those who would lose and those who would win, meaning that these differences will not remain under the radar of politics, and neither will any scientific evidence that would support one view or another, including evidence of the downsides of intervention or its sheer redundancy.

To sum up, a nudge is appropriate, insofar as it is both the least restrictive measure necessary to achieve a declared policy result that elicits subsidiary action by the state for a scientifically identified problem, and the least burdensome for the freedom of those subjected to this restriction. Soft interventionism is preferable to restrictions and commands insofar as they can be effective in achieving the public objective pursued in conformity to scientific guidance, at the same time, being the mildest in terms of the adverse effects on freedom. We now show how soft interventionism can apply within these constraints both at the margins of externalities and internalities, and with a case that is more centrally an internality.

\section{Entangled externalities and internalities}

The application of soft interventionism is particularly useful when the distinction between externalities and internalities is empirically inseparable, such as driving. A car accident can harm us and others, impose costs on relatives and entire families as well the local community. Traffic regulation illustrates an area where soft interventions can effectively supplement another form of regulation (cf. John 2018, 15) under the principles of subsidiarity, proportionality and consistency with scientific evidence. Road transit is critical to the functioning of market economies and people's pursuit of their own separate ends. Indeed, safe and rapid transport is such a central example of a common good that rules governing traffic are sometimes used as a concrete illustration of the value of the rule of law for a liberal society more generally (Schmidtz 2010). But the consequences of accidents mean that both learning to drive, and road guidance must be formal (it cannot be left to spontaneous trial and error) and subject to significant regulation.

There is a substantial body of tort law, typically managed between insurance companies, that address accidental harm and damage between road users. Yet governments consider tort law inadequate for preventing accidents and use escalating criminal penalties for dangerous and negligent driving, as well as sanctions for parking that disrupts the flow of traffic or creates potential hazards. Within this thick regulatory environment, few interventions directly mandate personal behavior because of self-harm. An exception is the introduction of mandatory seat belt laws where safety benefits are concentrated on car occupants rather than other road users (A. Cohen and Einav 2003). Other regulations focus on the automobiles 
themselves, with periodic new mandates for safety features, as well as requirements for regular inspections to test the roadworthiness of older vehicles.

There is, in addition, an enormous number of interventions that constitute 'nudges' in the form of road guides, warnings and reminders of speed limits and potential hazards. Traffic humps are another example of a kind of intervention that provides direct physical feedback to drivers who may well be driving within the speed limit but not as slow as to better ensure safety (Arbogast et al. 2018). Because of the external costs of collision, these are not generally considered paternalist interventions. Nevertheless, their scope is broader than what formal rules mandate. While some of these signs are designed to warn drivers against breaking a specified rule associated with a sanction, many other road signs are warning against acts that are either not subject to formal sanction or are essentially unenforceable unless a road traffic incident takes place (for example, reminders to take breaks from driving).

Many of these interventions are aimed at achieving a reduction in incidents for which there is already provision to internalize the costs (after all, every driver is compulsorily insured), and for which many of the costs and benefits are concentrated on the driver in any case. Insofar as they are effective, they are shifting driver behavior away from their spontaneous choice taken within known rules. From a narrow individualist standpoint, this would suggest that traffic regulators are departing from the framework of legal rules governing traffic. Indeed, from Rizzo and Whitman's $(2019,243)$ position, it might look as if these interventions involve imputing (unjustifiably) a preference for additional personal safety to road users that is not evident in their spontaneous behavior. On our account, safety is inevitably a joint enterprise that must combine driver decisions with a context specifically designed and improved to provide constant feedback based on evidence. Moreover, safe driving must be learnt and subject to reminders particularly for moments of distraction and fatigue. In that sense, there is no reason to exclude effective behavioral nudges provided they help drivers with safety and comfort, goals which almost any driver would plausibly pursue.

These interventions are implemented by private agents on their premises as well as public authorities on the road. However, if the roads happened to be private and the firms tasked with managing them introduced these soft interventions either spontaneously or in response to an assignment of tort liability, Rizzo and Whitman would have little cause to contest them. They would have been produced by the combination of personal choice, market actors and custom that they endorse. To a considerable extent, road safety is achieved through softer interventions rather than harsher penalties. 


\section{Extending the logic}

Although much of the new paternalist debate has focused on consumer behavior in private markets, some areas where there is the greatest scope for welfare-improving behavioral interventions is regarding citizens as public-service users (Guala and Mittone 2015). Road traffic regulation is exceptional in that it is one area where many people come at least into peripheral contact with the criminal justice system. Because road-users are comparatively wellrepresented in the political system, sanctions tend to be graduated, with the use of warnings in preference to penalties. ${ }^{3}$ Because nearly all drivers eventually receive a sanction, the political incentives tend to be aligned towards proportionality. However, in principle, nudges and reminders would improve other aspects of the justice system. For example, a recent study examines the impact of using "nudge" informed interventions to encourage defendants to attend their court dates (Fishbane, Ouss, and Shah 2020). Failure to appear before a court is a legal breach that leads to escalating sanctions, besides delaying the course of justice. So, it is in the interests of relevant parties for appointments to be kept, most of all the defendants. This applies even if attendance itself is a painful experience that some defendants might put off even at great future cost if not explicitly reminded.

If this were a relationship between a private firm, with a straightforward profit motive, and a consumer of a good or service, such reminders to receive the service would perhaps be more typically implemented (at least insofar as it is in the interests of the firm for their product to be utilized). Making it a state policy in such circumstances is a reasonable and legitimate extension. Moreover, such interventions do not involve fine-tuning against an imputed preference since the nudges are made to avoid deliberately harsher and escalating sanctions that the state authority itself will have to spend resources to mete out. In this sense, appropriate nudges can be explicitly justified as a subsidiary and proportionate measure, which would actually preclude a slippery slope to more heavy-handed intervention unless justified by the same standards.

\section{Suicide and overdose reduction}

Our next example illustrates soft interventionism within our suggested constraints in a case more straightforwardly conceived as an internality, albeit one that takes place over a shorter

\footnotetext{
${ }^{3}$ An exception, that crops up in parts of the United States, is where local traffic jurisdictions are controlled by governments that do not represent typical road users effectively and where police can use their sanction powers regulating traffic to raise revenue (Surprenant 2019; Brazil 2020).
} 
timescale than is the case for many other behavioral interventions. In the United Kingdom, regulations introduced in the late 1990s reduced the pack size of acetaminophen (there labelled paracetamol) and several other analgesics associated with accidental and suicidal overdose (Hawton et al. 2004; Bergen et al. 2010). The reforms also replaced bottles of tablets with individually sealed blister packs. While total sales rose and overall use of pain relief was apparently unaffected by the policy intervention, overdose deaths dropped significantly (Hawton et al. 2013). There is limited evidence for substitution effects. Peltzman (1975) effects, whereby imposed improvements in safety are offset through individuals adopting riskier personal behavior, are not in evidence either. So, these interventions have a plausible scientific basis.

Many suicides are impulsive (Turecki 2005). Suicidal ideation often involves highly specific modes of carrying out self-harming action. If thwarted, the individual actor does not predictably switch to what would logically represent a close substitute method (Daigle 2005). Failed attempts at suicide do not steadily predict repeat attempts (Yip et al. 2012). There is a rational suicide literature that explains some of these behaviors (Kimenyi and Shughart 1986). It is possible to explain the impulsivity and specific intent of a life-ending event through a rational choice model. At the same time, the attempt to explain suicide in this way can appear more like a reductio ad absurdum of the rational choice paradigm rather than a vindication of it because the logic seems to imply that any action, no matter how rash and anomalous with other aspects of personal utility, can be described as rational (cf. Murphy 2019). It seems more plausible to acknowledge that in some common cases the process of rational thought breaks down such that momentary choices can lead to tragic outcomes for the person making them. Relatively minor alterations to the social environment, such as changing the way that certain medicines are packaged for sale, can significantly reduce these tragic outcomes. Although suicide and deliberate self-harm have always been part of the human experience, the availability of some painkillers represents an additional danger because they can be surprisingly effective at causing death without warning. They are not associated with sensuous negative feedback that would be the case for violent methods of self-harm or of poisons found in the natural world.

A possible response to this is that private actors should be capable of introducing this kind of product safety improvement themselves if it is indeed welfare enhancing. After all, pharmacists have neither an individual nor collective interest in facilitating overdoses. So why were these policies not adopted spontaneously? It could be that the government's subsidiary role is about simply supplying evidence and aiding coordination between competitors in this 
sort of case. Alternatively, however, it might be that a marginal collective action problem exists: individual firms would benefit from being a sole provider of the traditional pill bottles as they are preferred by some customers, so they need a government mandate to ensure no one is competing along that margin. In any case, it seems that a government impetus was efficacious in this case and could be justified under the test of subsidiarity.

What makes this a relatively easy case against our benchmarks? First, it is (or at least can be) applied locally and generally with the support of private associations and firms. The imperative to reduce self-harm associated with analgesics is broadly shared across the entire community that is affected by the regulation, so it passes a test of subsidiarity. Unlike, for example, tobacco smoking, there is less of a social or cultural dimension to acetaminophen use. Indeed, acetaminophen does not have an alternative recreational use at all. So, it is not generally considered an indulgence to be affirmed, denied, or stigmatized. There is not a salient ethnic or class gradient to that kind of pain relief. Second, the negative outcome that it attempts to avoid is severe (suicide is a major cause of mortality) while the behavioral intervention is limited, hence proportional. Indeed, changes to the packaging of over-the-counter medicine is a minor intervention compared to the common alternative of making them prescription only. Finally, the intervention is based on scientific evidence which is frequently re-assessed in the academic literature.

Rizzo and Whitman do not address behavioral interventions to reduce suicide or overdose specifically. They do, however, support the rolling back of criminal prohibitions on recreational drugs and are content to endorse the substitution of hard prohibitions for nudges if that helps to reduce prohibitions, although they doubt soft interventions will work consistently even in this area (Rizzo and Whitman 2019, 428). We agree that hard prohibitions of recreational drugs are poor policy. They are arguably outstanding cases of policies that fail all three of our proposed tests as drug prohibition is encouraged by international treaties rather than decided locally, involve massively disproportional sanctions compared to the harms they purport to address, and are premised on poor quality scientific evidence (Mejía and Csete 2016). However, the case of acetaminophen package regulation in the United Kingdom shows that there are reasons to be more positive about some behavioral interventions than Rizzo and Whitman give credit. Moreover, the scope for such interventions goes beyond addictive and recreational drugs that have some risks and harms associated with them, but also to drugs that are meant to be taken purely for pain relief but are associated with accidental death and suicide.

\section{Conclusion}


From a classical liberal perspective, state interventions must be anchored to respect individual choices while acknowledging tensions regarding their consequences. In our account, welfareenhancing information is essential for facilitating cooperation and coordination in a complex social order where market-emergent heuristics may, in some cases, be seen as insufficient. The free play of market forces is a major force for disseminating knowledge throughout society but can occasionally leave people unduly exposed to risks of harm they may inflict on themselves and others, which can be addressed or mitigated by some form of public action. This is where there is a role for careful state intervention. In this context, soft interventions represent a proportionate substitute to direct regulation or paternalism regarding internalities and externalities. Rather than a slippery slope to unjustified intervention, soft interventionism is bound by the checks of proportionality and subsidiarity to improve our informational capacity without restricting our choices to choose our risks. Soft interventionism requires policymakers to opt for the least intrusive form of intervention, first and foremost nudges as a softer way to achieve legitimate public policy ends. This form of interventionism is compatible with classical liberal commitments.

\section{References}

Acemoglu, Daron, and James A. Robinson. 2019. The Narrow Corridor: States, Societies, and the Fate of Liberty. New York: Penguin Press.

Aligică, Paul Dragoș, Peter J. Boettke, and Vlad Tarko. 2019. Public Governance and the Classical-Liberal Perspective: Political Economy Foundations. New York City: Oxford University Press.

Allcott, Hunt, and Cass R. Sunstein. 2015. "Regulating Internalities." Journal of Policy Analysis and Management 34 (3): 698-705. https://doi.org/10.1002/pam.21843.

Arbogast, Helen, Melissa Patao, Natalie Demeter, Shelby Bachman, Elizabeth Devietti, Jeffrey S. Upperman, and Rita V. Burke. 2018. "The Effectiveness of Installing a Speed Hump in Reducing Motor Vehicle Accidents Involving Pedestrians under the Age of 21." Journal of Transport \& Health 8 (March): 30-34. https://doi.org/10.1016/j.jth.2017.11.004.

Barnett, Randy E. 2004. Restoring the Lost Constitution: The Presumption of Liberty. Princeton: Princeton University Press.

Bellisari, A. 2008. "Evolutionary Origins of Obesity." Obesity Reviews 9 (2): 165-80. https://doi.org/10.1111/j.1467-789X.2007.00392.x. 
Bergen, H., K. Hawton, K. Waters, J. Cooper, and N. Kapur. 2010. "Epidemiology and Trends in Non-Fatal Self-Harm in Three Centres in England: 2000-2007." The British Journal of Psychiatry 197 (6): 493-98. https://doi.org/10.1192/bjp.bp.110.077651.

Boettke, Peter J. 2002. "Information and Knowledge: Austrian Economics in Search of Its Uniqueness." The Review of Austrian Economics 15 (4): 263-74.

Boettke, Peter J. 2018. F. A. Hayek: Economics, Political Economy and Social Philosophy. Great Thinkers in Economics. London: Palgrave Macmillan.

Brazil, Noli. 2020. "The Unequal Spatial Distribution of City Government Fines: The Case of Parking Tickets in Los Angeles." Urban Affairs Review 56 (3): 823-56. https://doi.org/10.1177/1078087418783609.

Buchanan, James M. 2000. The Limits of Liberty: Between Anarchy and Leviathan. The Collected Works of James M. Buchanan, v. 7. Indianapolis: Liberty Fund.

Buchanan, James M. 2001. "Criteria for a Free Society." In Federalism, Liberty, and the Law, 173-84. The Collected Works of James M. Buchanan, v. 18. Indianapolis, Ind: Liberty Fund.

Buchanan, James M., and Roger D. Congleton. 2003. Politics by Principle, Not Interest: Toward Nondiscriminatory Democracy. Indianapolis: Liberty Fund.

Buturovic, Zeljka, and Slavisa Tasic. 2015. “Kahneman's Failed Revolution Against Economic Orthodoxy." $\quad$ Critical $\quad$ Review $27 \quad$ (2): $127-45$. https://doi.org/10.1080/08913811.2015.1068512.

Caldwell, Bruce. 2004. "Some Reflections on F.A. Hayek's The Sensory Order." Journal of Bioeconomics 6 (3): 239-54. https://doi.org/10.1007/s10818-004-5505-9.

Cherukupalli, Rajeev. 2010. "A Behavioral Economics Perspective on Tobacco Taxation." American Journal of Public Health 100 (4): 609-15. https://doi.org/10.2105/AJPH.2009.160838.

Cohen, Alma, and Liran Einav. 2003. "The Effects of Mandatory Seat Belt Laws on Driving Behavior and Traffic Fatalities." Review of Economics and Statistics 85 (4): 828-43. https://doi.org/10.1162/003465303772815754.

Cohen, Stanley. 2011. Folk Devils and Moral Panics: The Creation of the Mods and Rockers. Routledge Classics. Abingdon, Oxon; New York: Routledge.

Cowen, Nick. 2020. "Hayek: Postatomic Liberal.” In Critics of Enlightenment Rationalism, edited by Gene Callahan and Kenneth B. McIntyre, 179-92. Cham: Springer International Publishing. https://doi.org/10.1007/978-3-030-42599-9_12.

Cowen, Nick. 2021. Neoliberal Social Justice. Cheltenham, UK: Edward Elgar Publishing. 
Daigle, Marc S. 2005. "Suicide Prevention through Means Restriction: Assessing the Risk of Substitution." Accident Analysis \& Prevention $37 \quad$ (4): 625-32. https://doi.org/10.1016/j.aap.2005.03.004.

Delmotte, Charles, and Malte Dold. 2021. 'Dynamic Preferences and the Behavioral Case against Sin Taxes'. Constitutional Political Economy, March. https://doi.org/10.1007/s10602-021-09328-8.

Dold, Malte F., and Paul A. Lewis. 2021. "F.A. Hayek on the Political Economy of Endogenous Preferences: An Historical Overview and Contemporary Assessment." Working paper. https://ssrn.com/abstract=3860922.

Fishbane, Alissa, Aurelie Ouss, and Anuj K. Shah. 2020. "Behavioral Nudges Reduce Failure to Appear for Court." Science, October, eabb6591. https://doi.org/10.1126/science.abb6591.

Fuster, Joaquín M. 2011. “Hayek in Today’s Cognitive Neuroscience.” In Advances in Austrian Economics, edited by Leslie Marsh, 15:3-11. Emerald Group Publishing Limited. https://doi.org/10.1108/S1529-2134(2011)0000015006.

Gigerenzer, Gerd. 2008. "Why Heuristics Work.” Perspectives on Psychological Science 3 (1): 20-29. https://doi.org/10.1111/j.1745-6916.2008.00058.x.

Guala, Francesco, and Luigi Mittone. 2015. "A Political Justification of Nudging." Review of Philosophy and Psychology 6 (3): 385-95. https://doi.org/10.1007/s13164-015-02418.

Halpern, David. 2016. Inside the Nudge Unit: How Small Changes Can Make a Big Difference. Hawton, Keith, H. Bergen, S. Simkin, S. Dodd, P. Pocock, W. Bernal, D. Gunnell, and N. Kapur. 2013. "Long Term Effect of Reduced Pack Sizes of Paracetamol on Poisoning Deaths and Liver Transplant Activity in England and Wales: Interrupted Time Series Analyses.” BMJ 346 (feb07 1): f403-f403. https://doi.org/10.1136/bmj.f403.

Hawton, Keith, Sue Simkin, Jonathan Deeks, Jayne Cooper, Amy Johnston, Keith Waters, Morag Arundel, et al. 2004. "UK Legislation on Analgesic Packs: Before and after Study of Long Term Effect on Poisonings." BMJ 329 (7474): 1076. https://doi.org/10.1136/bmj.38253.572581.7C.

Hayek, Friedrich A. 1982a. Law, Legislation, and Liberty: A New Statement of the Liberal Principles of Justice and Political Economy. Reprinted 1993. Vol. 3. London: Routledge. 
Hayek, Friedrich A. 1982b. Law, Legislation, and Liberty: A New Statement of the Liberal Principles of Justice and Political Economy. Reprinted 1993. Vol. 2. London: Routledge.

Hayek, Friedrich A. von. 1937. "Economics and Knowledge." Economica 4 (13): 33-54. https://doi.org/10.2307/2548786.

Hayek, Friedrich A. von. 1945. "The Use of Knowledge in Society." American Economic Review 35 (4): 519-30.

Hayek, Friedrich A. von. 1952. The Sensory Order: An Inquiry into the Foundations of Theoretical Psychology. Chicago, Ill.: University of Chicago Press.

Hayek, Friedrich A. von. 1960. The Constitution of Liberty. Chicago [Ill.]: University of Chicago Press.

Hayek, Friedrich A. von. 1973. Law, Legislation, and Liberty: Rules and Order. Reprinted 1993. Vol. 1. London: Routledge.

Hayek, Friedrich A. von. 1981. "Kinds of Order in Society." New Individualist Review. http://files.libertyfund.org/files/2493/Hayek_KindsOrder1964.pdf.

Hayek, Friedrich A. von. 2007. The Road to Serfdom: Text and Documents. Definitive ed. The Collected Works of F.A. Hayek, v. 2. Chicago: University of Chicago Press.

Hayek, Friedrich A. von. 2014. "Competition as a Discovery Procedure.” In The Market and Other Orders, edited by Bruce Caldwell, 304-13. University of Chicago Press.

John, Peter. 2018. How Far to Nudge? Assessing Behavioural Public Policy. Cheltenham, UK; Northamption, MA: Edward Elgar.

Kahneman, Daniel. 2011. Thinking, Fast and Slow. London: Penguin Books.

Kahneman, Daniel, and Amos Tversky. 1979. "Prospect Theory: An Analysis of Decision under Risk." Econometrica 47 (2): 263-91.

Kahneman, Daniel, and Amos Tversky. 1984. "Choices, Values, and Frames." American Psychologist 39 (4): 341-50. https://doi.org/10.1037/0003-066X.39.4.341.

Kimenyi, Mwangi S., and William F. Shughart. 1986. "Economics of Suicide: Rational or Irrational Choice." Atlantic Economic Journal 14 (1): 120-21. https://doi.org/10.1007/BF02303514.

Lawler, Stephanie. 2005. "Disgusted Subjects: The Making of Middle-Class Identities." The Sociological Review $53 \quad$ (3): 429-46. https://doi.org/10.1111/j.1467954X.2005.00560.x. 
Mejía, Daniel, and Joanna Csete. 2016. "THE ECONOMICS OF THE DRUG WAR: UNACCOUNTED COSTS, LOST LIVES, MISSED OPPORTUNITIES.” New York: Open Society Foundations. https://doi.org/10.1163/2210-7975_HRD-9709-2016005.

Murphy, Ryan H. 2019. "The Rationality of Literal Tide Pod Consumption." Journal of Bioeconomics 21 (2): 111-22. https://doi.org/10.1007/s10818-019-09285-1.

Nutt, David. 2009. 'Equasy — An Overlooked Addiction with Implications for the Current Debate on Drug Harms'. Journal of Psychopharmacology 23 (1): 3-5. https://doi.org/10.1177/0269881108099672.

Peltzman, Sam. 1975. "The Effects of Automobile Safety Regulation.” Journal of Political Economy 83 (4): 677-725. https://doi.org/10.1086/260352.

Pennington, Mark. 2008. "Classical Liberalism and Ecological Rationality: The Case for Polycentric Environmental Law." Environmental Politics 17 (3): 431-48. https://doi.org/10.1080/09644010802055659.

Polanyi, Michael. 2000. "The Republic of Science: Its Political and Economic Theory." Minerva 38 (1): 1-21.

Popper, Karl. 1945. The Open Society and Its Enemies. London: Routledge.

Rizzo, Mario J. 2019. “Inconsistency Is Not Pathological: A Pragmatic Perspective.” Mind \& Society 18 (1): 77-85. https://doi.org/10.1007/s11299-019-00211-6.

Rizzo, Mario J., and Malte F. Dold. 2020. "Can a Contractarian Be a Paternalist? The Logic of James M. Buchanan's System." Public Choice 183 (3-4): 495-507. https://doi.org/10.1007/s11127-020-00804-7.

Rizzo, Mario J., and Glen Whitman. 2019. Escaping Paternalism: Rationality, Behavioral Economics, and Public Policy. Cambridge Studies in Economics, Choice, and Society. Cambridge, United Kingdom; New York, NY: Cambridge University Press.

Scheall, Scott. 2020. Hayek and the Epistemology of Politics. Routledge Studies in the History of Economics 228. Abingdon, Oxon; New York, NY: Routledge.

Schliesser, Eric. 2019. "Walter Lippmann: The Prophet of Liberalism and the Road not Taken." Journal of Contextual Economics - Schmollers Jahrbuch 139 (2-4): 349-64. https://doi.org/10.3790/schm.139.2-4.349.

Schliesser, Eric. 2021. "Political Epistemology, Scheall and Transition Problems" 9 (3+4): 3542.

Schmidtz, David. 2010. "Property and Justice." Social Philosophy and Policy 27 (1): 79-100. https://doi.org/10.1017/S0265052509990045. 
Sunstein, Cass R. 2021. "Hayekian Behavioral Economics." Behavioural Public Policy, March, 1-19. https://doi.org/10.1017/bpp.2021.3.

Surprenant, Chris W. 2019. "Policing and Punishment for Profit." Journal of Business Ethics 159 (1): 119-31. https://doi.org/10.1007/s10551-017-3744-7.

Thaler, Richard H, and Cass R Sunstein. 2009. Nudge: Improving Decisions about Health, Wealth and Happiness. London: Penguin Books.

Trantidis Aris. 2015. "Clientelism and the Classification of Dominant Party Systems." Democratization 22 (1): 113-131. https://doi.org/10.1080/13510347.2013.825608.

Trantidis, Aris, and Nick Cowen. 2020. "Hayek versus Trump: The Radical Right's Road to Serfdom.” Polity 52 (2): 159-88. https://doi.org/10.1086/707769.

Tullock, Gordon. 1987. The Organization of Inquiry. Lanham, MD: University Press of America.

Turecki, Gustavo. 2005. "Dissecting the Suicide Phenotype: The Role of Impulsive Aggressive Behaviours." J Psychiatry Neurosci 30 (5): 398-408.

Weintraub, E. Roy. 1993. "Neoclassical Economics." In The Concise Encyclopedia of Economics, edited by David Henderson. Library of Economics and Liberty.

Yip, Paul SF, Eric Caine, Saman Yousuf, Shu-Sen Chang, Kevin Chien-Chang Wu, and YingYeh Chen. 2012. "Means Restriction for Suicide Prevention.” The Lancet 379 (9834): 2393-99. https://doi.org/10.1016/S0140-6736(12)60521-2. 